\title{
A JUDICIALIZAÇÃO DOS MEDICAMENTOS DE ALTO CUSTO NO BRASIL E A TEORIA DOS CUSTOS DOS DIREITOS
}

\author{
Leandro Correa de Oliveira ${ }^{58}$ \\ Adriano Rodrigo Reis ${ }^{59}$
}

Recebido em: 10/08/2019

Aprovado em: 06/02/2020

\section{RESUMO}

Este Trabalho objetiva analisar as decisões do Supremo Tribunal Federal brasileiro nas demandas por medicamentos de alto custo investigando como vem sendo tratado o problema dos custos dos direitos, ou seja, qual a importância (valor) dada pelo Tribunal às questões de ordem financeiroorçamentária em face de argumentos ético-jurídicos como o mínimo existencial e a dignidade da pessoa humana. Diante do crescente fenômeno da judicialização da saúde, o objetivo principal é analisar os efeitos teóricos e práticos da discussão acerca da dimensão positiva dos direitos fundamentais, sob uma perspectiva pragmática, para a efetivação do direito social à saúde, sobretudo da assistência farmacêutica. Não obstante o reconhecimento da dimensão positiva presente em todos os direitos, quando descritivamente analisados, conforme demonstra Cass Sunstein e Stephen Holmes, verifica-se que a jurisprudência brasileira tem sustentado que nenhum argumento de ordem financeiro-orçamentária pode limitar o direito ao recebimento de medicamentos de alto custo. Tal posicionamento, entretanto, encontra dificuldades em se adequar aos ideais de universalidade e igualdade, bem como, à justiça distributiva, por atender somente uma parcela da população em detrimento de outra ainda maior.

Palavras-chave: Direito à saúde. Medicamentos de alto custo. Custo dos direitos.

\section{INTRODUÇÃO}

\footnotetext{
${ }^{58}$ Doutor em Direito pela Faculdade Estácio de Sá. Mestre em Direito do Estado pela Universidade Federal do Paraná. Professor dos cursos de graduação e mestrado da Faculdade de Direito do Sul de Minas. Advogado.

${ }^{59}$ Mestrando em Direito pela Faculdade de Direito do Sul de Minas. Pós-Graduado em Direito Médico e da Saúde pela Faculdade de Direito de Varginha. Pós-Graduado em Direito Constitucional pela Faculdade Estácio de Sá.
} 
O mundo moderno ocidental, nas últimas décadas, tem observado uma acentuada transferência de poder de instituiçõos políticas representativas para os tribunais. Este recurso, cada vez maior, a tribunais e a procedimentos judiciais para a resolução de dilemas morais relevantes, de questões de política pública e de controvérsias políticas, é uma tendência do fenômeno conhecido por “judicialização da política” (HIRSCHL, 2006).

No âmbito da saúde pública brasileira, esta judicialização ocorre através do aumento de processos judiciais que, geralmente, postulam prestações materiais de saúde ao Estado como, por exemplo, o fornecimento de medicamentos, suplementos alimentares, órteses e próteses; a criação de vagas de UTIs e leitos hospitalares; a contratação de servidores de saúde; a realização de cirurgias e exames; o custeio de tratamento fora do domicílio, inclusive no exterior, entre outros. ${ }^{60}$

De acordo com dados do Ministério da Saúde, de 2010 até Julho de 2016 houve um aumento de $727 \%$ nos gastos da União com ações judiciais para aquisição de medicamentos, equipamentos, insumos, realização de cirurgias e depósitos judiciais, com custos para a União na ordem de R \$ 3,9 bilhões no cumprimento das sentenças judiciais ${ }^{61}$. No caso específico do fornecimento de medicamentos, dados do Guia Interfarma de 2018, sugerem que os gastos fiquem entre US\$ 38

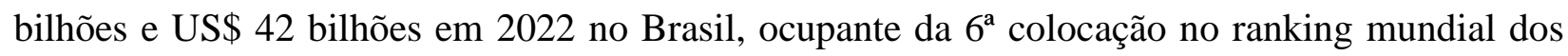
mercados farmacêuticos. O guia também destaca o crescimento do mercado farmacêutico institucional de $11,6 \%$ nos últimos doze meses, impulsionado por terapias inovadoras. ${ }^{62}$

No Brasil, um país onde a desigualdade social reflete substancialmente na saúde de seus cidadãos (TRAVASSOS, 2000), a judicialização da saúde tem levado à percepção de que todas as tecnologias existentes no mercado mundial são passíveis de serem custeadas pelo Estado e que o constituinte conferiu a todos os brasileiros o direito a melhor prestação de saúde existente no mundo. Acredita-se no mito do "governo grátis" (CASTRO, 2014), como se não existissem limitações de ordem financeiro-orçamentárias e de recursos humanos e tecnológicos. No entanto, conforme afirma Sunstein e Holmes, nenhum direito cuja eficácia pressupõe o gasto seletivo de recursos do contribuinte pode, em última instância, ser protegido unilateralmente pelo Poder

\footnotetext{
${ }^{60}$ Conforme destacado pelo Ministro Gilmar Mendes em seu voto no julgamento da Suspensão de Tutela Antecipada 175/CE. BRASIL. Supremo Tribunal Federal. STA 175 - AgR/CE, Rel. Min. GILMAR MENDES. Julgamento:17.3.2010. DJe n ${ }^{\circ}$ 76. Publicação: 30/04/2010.

${ }^{61}$ Informação publicada no portal de notícias na página do site cnj.jus, em 23/08/2016, sob o título: CNJ e Ministério da Saúde firmam acordo para criação de banco de dados. Disponível em: http://www.cnj.jus.br/ noticias/cnj/83208cnj-e-ministerio-da-saude-firmam-acordo-para-criacao-de-banco-de-dados Acesso em: 24/07/2018.

${ }^{62}$ Disponível em: https://www.interfarma.org.br/guia/guia-2018/dados_do_setor . Acesso em: 25 Mai 2019.
} 
Judiciário sem observância das consequências orçamentárias que afetam a competência dos outros Poderes (SUNSTEIN, 1999. p. 97).

O Supremo Tribunal Federal, ao julgar as demandas por medicamentos de alto custo (ou medicamentos excepcionais) $)^{63}$, geralmente, tem decidido com base na teoria dos direitos fundamentais, adotando uma perspectiva substancialista do direito. Em suas decisões sempre há a predominância do direito a saúde - qualificada como um direito subjetivo público ligado à ideia de liberdade fática e à própria vida - sobre qualquer tipo de argumento contrário - estes, muitas das vezes, são classificados pelo Tribunal como "interesses secundários do Estado". ${ }^{64}$ Contudo, tais conflitos são policêntricos e ultrapassam fatores exclusivamente jurídicos, assentando-se também em questões de ordem econômica, política e técnica - como por exemplo, a Medicina Baseada em Evidências, a qual busca verificar a eficácia, a efetividade e a segurança do medicamento a ser disponibilizado (SCHULZE, 2018. p.78).

$\mathrm{O}$ atendimento das necessidades por saúde de toda população, deve ocorrer pela via das políticas públicas, dentro dos limites financeiro-orçamentários do Estado. Este fato impõe certa deferência às escolhas alocativas tomadas previamente no âmbito dos órgãos políticos representativos e parece ser o caminho mais adequado para concretização dos direitos que exigem prestações estatais positivas, por adequar-se melhor ao ideal de igualdade e universalidade, bem como à justiça distributiva. O "emocionalismo jurídico", que acredita no discurso de proteção jurisdicional dos direitos fundamentais como a porta de entrada da realização de um senso pessoal de justiça, é uma ingenuidade que, nas palavras de Vanice R. L. do Valle (2016. p.184) "pode conduzir a graves distorções na perspectiva macro do atuar da Administração Pública".

O impacto financeiro provocado pelo crescente número de condenações judiciais traz dificuldades administrativas aos gestores de saúde pública, desorganizando as políticas previamente programadas e em fase de implementação. Uma das consequências é a criação de um

\footnotetext{
${ }^{63}$ Conforme dispõe a Portaria $\mathrm{n}^{\mathrm{o}} 1.554$ de 30 de julho de 2013 expedida pelo Ministério da Saúde, fazem parte do grupo 1 do Componente Especializado da Assistência Farmacêutica (CEFA). Ministério da Saúde. Gabinete do Ministro. PORTARIA N ${ }^{\circ}$ 1.554, DE 30 DE JULHO DE 2013. (...) Art. $5^{\circ}$ O Grupo 1 é definido de acordo com os seguintes critérios específicos: I - maior complexidade do tratamento da doença; II - refratariedade ou intolerância a primeira e/ou a segunda linha de tratamento; III - medicamentos que representam elevado impacto financeiro para o Componente Especializado da Assistência Farmacêutica (...) Disponível em: http://bvsms.saude.gov.br/bvs/saudelegis/gm/2013/prt1554_30_07_2013.html . Acesso em: 25 Mai 2019.

64 “O Estado deve assumir as funções que lhe são próprias, sendo certo ainda, que problemas orçamentários não podem obstaculizar o implemento do que previsto constitucionalmente”. STF. RE 195.192-3/RS; Rel. Marco Aurélio, julgamento em 22/02/00, publicado no DJ 31-03-2000; "por razões ético-jurídicas, o direito a vida e à saúde prevalece sobre o interesse financeiro e secundário do Estado". STF. AgR no RE 271.286-8/RS; Rel. Celso de Mello, julgamento em 12/09/00; publicado no DJ 24-11-2000.
} 
sistema de saúde de duas portas: uma para aqueles que vão até ao Judiciário, para quem a vida não tem preço, e conseguem acesso irrestrito aos recursos estatais para satisfazer suas necessidades por saúde; outra para o restante da população que, inevitavelmente, tem acesso limitado, e mais limitado ainda pelo redirecionamento de recursos que beneficiam aqueles que entraram pela outra porta (FERRAZ, 2014).

Por um lado, o indeferimento do pedido de um medicamento por um magistrado, por não constar ou não preencher todos os requisitos estabelecidos no ordenamento jurídico, pode se tornar um drama, pois o demandante é uma pessoa física que possui rosto, identidade e nome. Por outro lado, existem milhares de pessoas vítimas de doenças relacionadas à falta de saneamento básico, ou das chamadas "doenças da miséria” ou negligenciadas. Em ambos os casos, sempre haverá uma escolha, explícita ou não, que priorizará certas situações de necessidade em detrimento de outras (BARCELLOS, 2010, p. 803).

Buscando discutir os problemas em torno da concretização do direito à saúde, o artigo analisa a atuação do Poder Judiciário, sobretudo do Supremo Tribunal Federal, nas questões envolvendo as demandas por medicamentos de alto custo e suas considerações acerca dos custos dos direitos. Para tanto, o estudo divide-se em três partes. Na primeira parte, o objetivo é analisar o posicionamento da doutrina pátria ao reconhecer a existência de reservas materiais como limites à efetivação dos direitos sociais fundamentais, e a garantia de um mínimo existencial.

$\mathrm{Na}$ segunda parte, é analisada a teoria dos custos dos direitos desenvolvida pelos doutrinadores norte-americanos Stephen Holmes e Cass Sunstein em sua obra "The Cost of Rights: Why Liberty Depends on Taxes" (1999). Buscou-se destacar a importância do reconhecimento dos custos inerentes a todos os direitos sob uma perspectiva descritiva e pragmática, fato que impõe a necessidade de tratamento de todos os direitos com responsabilidade, o que nos leva ao estudo da extensão do direito à saúde e a possibilidade de sua restrição.

Por fim, na terceira parte, verifica-se o posicionamento do Supremo Tribunal Federal ao decidir sobre demandas por medicamentos de alto custo, em seu histórico jurisprudencial, e os efeitos práticos da teoria dos custos dos direitos na lógica argumentativa das decisões analisadas. Diante da variedade de tipos de prestações assistenciais de saúde demandadas judicialmente, foram analisados apenas os pedidos por medicamentos de "alto custo", utilizando-se da ferramenta de pesquisa de jurisprudência disponível no portal do Supremo Tribunal Federal ${ }^{65}$.

${ }^{65}$ Disponível em http://www.stf.jus.br/portal/jurisprudencia/pesquisarJurisprudencia.asp . Acesso em: 21 Jan. 2019. 


\section{DA RESERVA DO POSSÍVEL À TEORIA DOS CUSTOS DOS DIREITOS}

A análise dos deveres imbricados no direito à saúde leva à delimitação das distintas e possíveis dimensões dos direitos fundamentais: a dimensão defensiva (negativa) e a dimensão prestacional (positiva). A primeira busca garantir ao titular do direito a proteção contra ingerências e agressões que possam ameaçar ou interferir no exercício do direito, praticadas pelo Estado ou por particulares. A dimensão prestacional, por sua vez, trata da realização de uma atividade por parte do destinatário, geralmente a Administração Pública, por meio da qual se torne viável a fruição do direito por quem o possua. É consubstanciada, portanto, no fornecimento direto de serviços e bens materiais ao titular do direito fundamental.

O pensamento jurídico brasileiro tem destacado diversos aspectos de tal diferenciação ao tratar do direito à saúde. Ingo Wolfgang Sarlet sustenta que o direito à saúde pode ser reconduzido a ambas as categorias, dependendo de sua função no caso concreto. De um lado, como direito de defesa ao impedir ingerências estatais ou de terceiros indevidamente na saúde do titular. De outro, como direito a prestações materiais quando impõe ao Estado a realização de políticas públicas que busquem atender as necessidades por saúde da população como, por exemplo, o fornecimento de medicamentos, o atendimento médico e hospitalar, a realização de exames, e diversas outras prestações necessárias à realização concreta daquele direito (SARLET, 2001).

É justamente por conta de sua condição de direito a prestações materiais em face do Estado, que os direitos sociais - dentre eles o direito à saúde - tem destacada sua dimensão econômica. Contudo, isto não significa que os direitos individuais, ligados à ideia de liberdade e defesa em geral, dispensem um conjunto de medidas estatais positivas. Após a "viragem paradigmática" do velho Estado liberal para o novo Estado democrático e social, conforme destaca Emerson Merlin Clève, o Estado deixou de ser o único violador dos direitos e liberdades individuais, passando, necessariamente, a ser um defensor dos direitos destes mesmos indivíduos contra si mesmos. Isto levou a existência de direitos negativos com dimensões positivas e direitos positivos com dimensões negativas (CLÈVE, 1999).

Embora se reconheça que a realização e a garantia de qualquer direito custe dinheiro, parte da doutrina insiste na existência da diferença dos custos para a concretização dos direitos sociais e 
econômicos em comparação com os direitos civis e políticos (SILVA, 2008). Os gastos comuns a ambas as espécies de direitos seriam os gastos institucionais, ou seja, os recursos dispendidos na manutenção das instituições políticas, judiciais e de segurança (ABRAMOVICH, 2004, p.23). A diferença estaria, portanto, nos gastos com a implementação dos direitos sociais no caso concreto, por exigir prestações materiais específicas. O custo decorrentes de decisões que obriguem o Poder Público a pagar medicamentos de alto custo são muito maiores, por exemplo, que os comparados com as decisões que obriguem o Estado a não interferir na liberdade de expressão.

Esta reserva material que limita a efetivação dos direitos fundamentais, e particularmente, os direitos sociais de cunho prestacional, é denominada pela doutrina de reserva do possível (FIGUEIREDO, 2007). Ela parte do pressuposto de que as prestações estatais estão sujeitas a limites materiais ingênitos, oriundos da escassez de recursos financeiros pelo Poder Público, razão pela qual, a ampliação da rede de proteção social dependeria da existência de disponibilidade orçamentária para tanto. A concretização dos direitos fundamentais sociais, portanto, fica condicionada ao montante de recursos previstos nos orçamentos das respectivas entidades públicas para tal finalidade, haja vista que, o orçamento autoriza a despesa pública, que se realiza de acordo com as prestações orçamentárias.

A cláusula da reserva do possível é um conceito importado do direito comparado germânico, construído pela jurisprudência do Tribunal Constitucional Federal Alemão. Surgiu no ano de 1972, na decisão conhecida por números clausus $^{66}$, que tratou do direito a vagas em universidades públicas, entendendo o Tribunal que os direitos fundamentais a prestações positivas deveriam ser limitados aos casos em que o indivíduo poderia racionalmente exigi-los da sociedade. $\mathrm{O}$ argumento foi de que, dentre as atribuições do legislador, cabe a ele observar também outros interesses da sociedade, sendo imprescindível preservar o equilíbrio econômico global, deixando de onerar, exageradamente, a comunidade com a instituição de despesas. Logo, uma pretensão subjetiva e ilimitada às custas da comunidade é incompatível com os princípios do Estado Social. ${ }^{67}$

\footnotetext{
${ }^{66}$ ALEMANHA. Tribunal Constitucional Federal (BVerfG). 1 BvL 32/70 e 25/71. J. 18.07.1972. BVerfGE $33,303$. NJW 1972, 1561.

${ }^{67}$ As demais ocasiões em que o fundamento da reserva do possível foi utilizado na Alemanha, conforme Gaier, foram: (1) em 1990, quando o Tribunal Constitucional alemão invocou a reserva do possível para justificar a constitucionalidade da redução do auxílio-criança para pais com nível de renda elevado; (2) em 1992, quando o Tribunal decidiu sobre a possibilidade do tempo gasto na educação dos filhos ser considerado para efeito de cálculo da aposentadoria, levando a um benefício previdenciário de maior valor; (3) em 1998, onde se discutiu sobre o reembolso das despesas pelos cuidados de crianças em jardins de infância se poderiam ser escalonadas de acordo com a renda familiar; (4) em 2001 quando tratou de uma contribuição obrigatória para a assistência decorrente de prestações que financiam idosos necessitados de cuidados especiais; e (5) em 2004, em uma decisão sobre a Lei de Indenização
} 
Para a jurisprudência do Tribunal Constitucional Alemão, a reserva do possível é o meio efetivo em que o legislador mantém uma margem de manobra de conformação política. Pode ser compreendida como restrições ou limitações a um "mínimo existencial" de direitos sociais fundamentais originários, considerando ser somente fora do âmbito de proteção desse mínimo que tais limites se justificam constitucionalmente enquanto não houver orçamento, ou políticas públicas que o compreenda, indicando quais prestações sociais devem ser suportadas pela sociedade (PERLINGEIRO, 2013).

O problema da diferenciação de um mínimo existencial como um núcleo essencial sempre exigível se encontra na definição do limite desta exigibilidade de forma incondicional. A terminologia utilizada para a exigibilidade dos direitos leva a uma aplicação binária - exigível ou não-exigível - enquanto a noção de mínimo existencial inclui enorme gradação, não existindo divisões nítidas. Portanto, não há como saber se a prestação é exigível incondicionalmente ou não, pois a exigibilidade não decorre apenas de características ônticas da necessidade, mas também da excepcionalidade da situação concreta (AMARAL, 2001. p. 213).

Reconhecer a eficácia jurídica dos comandos constitucionais sobre o direito à saúde é admitir que um conjunto de prestações materiais deste direito são exigíveis perante o Poder Judiciário e que os demais órgãos do Estado têm o dever de colocar a disposição das pessoas tais prestações. Contudo, a dificuldade é definir quais destas prestações de saúde devem ser oferecidas pelo Poder Público, ou seja, quais prestações podem ser exigidas dentro de um quadro de recursos limitados.

A posição que prevalece na doutrina brasileira, portanto, é de que a cláusula da reserva do possível funciona como um limite às prestações estatais positivas, não afetando diretamente o mínimo existencial dos direitos sociais fundamentais no caso concreto, conforme a regra da proporcionalidade. Os direitos individuais, ligados à ideia de liberdade, por serem qualificados como negativos ou por demandarem prestações não-fáticas, na prática, podem ser efetivados sem a necessidade de observar as reservas orçamentárias, deixando o problema dos custos para o segundo plano.

de Vítimas que regulamenta o apoio do Estado a vítimas de crimes violentos, oportunidade em que a reserva do possível foi vinculada à ideia da autocontenção judicial (GAIER, 2011). 


\section{A TEORIA DOS CUSTOS DOS DIREITOS: UMA PERSPECTIVA PRAGMÁTICA DOS DIREITOS FUNDAMENTAIS}

A teoria dos custos dos direitos parti de um modelo de pensamento aprofundado na obra de Stephen Holmes e Cass Sunstein, The Cost of Rights: Why Liberty Depends on Taxes (1999), reconhecendo que todos os direitos - mesmo aqueles tradicionais ligados à ideia de liberdade - são positivos e, portanto, demandam prestações públicas do Estado para sua concretização. Os autores partem de um conceito pragmático de direito subjetivo, afirmando que nenhum direito é absoluto caso custe algo ao cofres públicos. Não há como definir um direito, de forma descritiva, abstraindoo da realidade concreta, isto é, do contexto em que vivemos, razão pela qual, julgamentos sobre questões de valor, fato e dano mudam com o tempo e lugar. Um bom exemplo é o significado da liberdade de expressão na jurisprudência constitucional americana contemporânea, o qual não é o mesmo de cinquenta ou cem anos atrás (SUNSTEIN, 1999, p.123).

Tendo em vista esta realidade instável, contextual, não devemos reputar os direitos (rights) como uma situação ideal de caráter absoluto. É mais realista e mais produtivo definir os direitos como poderes individuais, derivados da filiação a uma comunidade política, de invocar os seletivos investimentos dos recursos coletivos escassos desta mesma comunidade. As circunstâncias cronológicas e espaciais somadas aos condicionamentos econômicos e financeiros é que irão definir quais são as prioridades desta comunidade e, consequentemente, qual o conteúdo do direito.

Os autores explicam que os direitos, observados por uma perspectiva moral (jusnaturalista), são aspirações que vinculam a consciência, impondo deveres morais universalmente aplicáveis e não obrigações em razão da lei. Já, os direitos descritivamente analisados (SUNSTEIN, 1999, p.16), no seu sentido jurídico, teriam “dentes” (SUNSTEIN, 1999, p. 17), ou seja, seriam poderes concedidos pela comunidade política, que, como qualquer outro poder, poderiam ser utilizados tanto para o bem como para o mal. Daí surge a necessidade de sua restrição e proteção, como por exemplo a liberdade de expressão, que, se mal utilizada, pode colocar em risco até mesmo a segurança pública. A crítica feita aos teóricos morais se deve, porque, normalmente, deixam de considerar que os direitos têm custos e que os recursos são finitos, escassos, deixando de lado a questão da justiça distributiva.

Um exemplo utilizado pelos autores é o clássico direito (subjetivo) de propriedade que só existe porque a posse e uso são criados e regulamentados por lei. Trata-se de um direito positivo 
porque ela é mantida todos os dias pela ação do Estado de forma positiva, através do trabalho, tanto preventivo quanto repressivo, de policiais e bombeiros para sua defesa e conservação, bem como por todo o aparato e estrutura do sistema de justiça para sua garantia. Seu conteúdo, como "santuário inviolável”, só tem relevância se as autoridades públicas usarem a coerção para defendêla das intromissões e invasões de terceiros (SUNSTEIN, 1999, p. 59).

Todas estas ações são financiadas com receitas públicas, com os recursos oriundos da tributação paga pelo bolso dos contribuintes. Na visão dos autores, a propriedade, vista como um típico direito de liberdade, tem caráter positivo, e não está ligada a uma abstenção do Poder Público, como comumente é dito. A afirmação de que um governo liberal deve se abster de violar direitos, de "respeitá-los", é, no fundo, uma falácia porque reduz o papel do governo ao de um observador não participante. Um sistema legal liberal não apenas protege e defende a propriedade, mas, a define e cria (SUNSTEIN, 1999, p. 60).

Esta assertiva é, em certa medida, reproduzida no Brasil, por Ricardo Lobo Torres quando afirma que as obrigações tributárias não preexistem à Constituição, mas nascem com e através dela, sendo que os tributos são o preço da liberdade, no sentido de que se constituem no espaço aberto pelos direitos fundamentais e visam a sua garantia. O princípio do Estado Fiscal sinaliza no sentido de que o Estado Democrático de Direito vive de tributos que constituem o preço da liberdade, são cobrados de acordo com os princípios de justiça e de segurança e se distribuem segundo as escolhas orçamentárias (TORRES, 2009, p. 312).

Uma vez que o Estado é imprescindível à criação e efetivação dos direitos, e tendo em vista que o Poder Público apenas funciona em virtude das contingências de recursos econômicofinanceiros apreendidos junto aos indivíduos singularmente considerados, verifica-se que os direitos apenas existirão onde houver fluxo orçamentário que o permita. Logo, a liberdade pessoal, como os americanos valorizam e experimentam, segundo Sunstein e Holmes, pressupõe a cooperação social administrada por funcionários do governo. O "reino privado" tão prestigiado pelos americanos é sustentado, e mesmo criado pela ação pública. Até mesmo o cidadão mais "auto-suficiente" não pode cuidar de seu bem-estar material, autonomamente, sem o apoio de todos os cidadãos ou funcionários públicos (SUNSTEIN, p. 14).

Aliados a um pensamento republicanista, Sunstein e Holmes (1988), desconhecem direitos criados antes da formação política. Para eles a esfera privada é produto de decisões públicas, que muitas vezes justificam a existência de setores de reconhecimento da autonomia privada, mas não 
de diretos naturais ou pré-políticos (GALDINO, 2002. p. 261). Logo, a intervenção estatal na esfera privada não é uma exceção, mas sim, uma precondição de funcionamento dos mercados denominados "livres e privados". Para os autores, um Estado capaz de reprimir de maneira confiável a força e a fraude e fazer valer os direitos de propriedade é uma conquista cooperativa de primeira magnitude, e o mundo infelizmente está repleto de exemplos negativos. Mas se os direitos privados dependem essencialmente de recursos públicos, não pode haver oposição fundamental entre "governo" e "livre mercado", nenhuma contradição entre cooperação social politicamente orquestrada e liberdade individual (SUNSTEIN, 1999, p. 64).

A teoria dos custos dos direitos defende, portanto, uma mudança no conceito de direito subjetivo, seja ele de caráter negativo (liberdades individuais e políticas) ou positivo (direitos sociais e econômicos) conforme a distinção feita pela maioria da doutrina, por inserir a perspectiva dos custos. Sob esta perspectiva todos os direitos, descritivamente analisados, são positivos. Logo, o contraste convencional entre direitos de segunda geração - vistos como aspirações ou ideias a serem sempre perseguidos, portanto ilimitados - e os direitos de primeira geração - relacionados às liberdades clássicas voltados a não intervenção do governo, portanto, limitados - não se sustenta. "Nossa liberdade em relação à interferência do governo não é menos dependente do orçamento do que o nosso direito à assistência pública" (SUNSTEIN, 1999, p. 119).

Todos os direitos, quando vistos como aspirações, são ilimitados pelo simples fato de que todos eles têm custos e, portanto, nunca poderão ser perfeitamente ou completamente protegidos. Não obstante, os argumentos filosóficos demonstrarem que as garantias mínimas (mínimo vital ou existencial) merecem ser classificadas como interesses humanos básicos - visto que uma pessoa não pode levar uma vida decente sem determinados níveis mínimos de alimentação, abrigo e assistência médica -, nenhum único direito que seja considerado importante pode ser concretizado com segurança se o tesouro público estiver vazio. Todos os direitos são protegidos até certo ponto, e esse grau de proteção dependerá em grande parte das decisões orçamentárias sobre como alocar os recursos públicos escassos. "Se os direitos têm custos, goste ou não, a política é um trunfo" (SUNSTEIN, p. 121).

Por fim, vale destacar que a ideia de que alguns direitos nada custam, ou são gratuitos (porque de cunho negativo não exigem prestações materiais do Estado) é equivocada, porque acaba gerando irresponsabilidades. Ao se reconhecer que todos os direitos têm custos, e que os recursos são oriundos da captação feita na coletividade (financiados pelos indivíduos), independentemente 
de sua classificação como de liberdade ou sociais e econômicos, constatamos que os recursos públicos não são suficientes para cumprir (totalmente) todos os ideais sociais, sendo necessário fazer escolhas alocativas e, até mesmo, trágicas. E isto leva ao reconhecimento de que os direitos devem ser exercitados com responsabilidade (SUNSTEIN, p. 146).

Ter responsabilidade nas escolhas alocativas e no uso dos recursos públicos é também reconhecer que, não somente os direitos sociais e econômicos são positivos por dispenderem recursos financeiros (orçamentários) e necessitarem de prestações materiais, mas também que os clássicos direitos de liberdade, os quais não são absolutos, estão, portanto, também sujeitos às escolhas trágicas. Isso impede que se faça uso ou manipulação ideológica da diferenciação direitos positivos/direitos negativos. Neste sentido, Michel Villey afirma que "sob a aparência de proporcionar a 'todos' satisfações infinitas, o sistema gira em benefício do 'alguns'. É difícil conceder algum direito subjetivo a uns, se não for em detrimento dos outros" (VILLEY, 2008. p.155).

Os custos, portanto, não devem ser vistos somente como óbices à concretização dos direitos fundamentais, mas também como pressupostos à sua existência. Não é a exaustão da capacidade orçamentária que, necessariamente, frustrará a efetivação destes direitos, mas sim a escolha política em deixar mais protegido parte de determinado direito em detrimento de outro. Daí a responsabilidade no estabelecimento e observância dos critérios de alocação dos recursos públicos, estabelecidos pelo Poder Público para o atendimento às demandas por prestações, mesmo que essenciais (AMARAL, 2001. p. 214). É possível acabar com o analfabetismo ou erradicar as doenças endêmicas, mas é preciso decidir onde se deve gastar, pois no âmbito orçamentário, há uma decisão política que prioriza sua realização (SCAFF, 2018). O conceito de escolhas públicas é eminentemente político e parte das opções políticas que são possíveis de serem realizadas com os recursos existentes.

\section{A JUDICIALIZAÇÃo dOS MEDICAMENTOS DE ALTO CUSTO NO ÂMBITO DO SUPREMO TRIBUNAL FEDERAL E O CUSTO DOS DIREITOS}

No âmbito do Supremo Tribunal Federal, foi no início da década de 1990 que as demandas por medicamentos de alto custo começaram a se destacar, sobretudo para o tratamento do 
HIV/AIDS. Foi um momento de construção dos primeiros critérios e parâmetros sobre o tema, os quais tem sido motivo de discussão até os dias de hoje. A partir dos anos seguintes, as demandas passaram a incluir outros tipos de medicamentos, para tratamento de outras doenças como o câncer e doenças raras, bem como, outras formas de assistência estatal à saúde, como pedidos por tratamentos diversos, insumos, cirurgias, vagas em leitos de UTI, entre outros.

Dentre os precedentes mais remotos sobre o tema da judicialização da saúde, podemos destacar a decisão monocrática na Suspensão de Segurança nº 659/RS, de relatoria do Min. Carlos Velloso, de 22 de julho de $1994^{68}$ julgada em conjunto com a SS 674/RS. O caso envolveu uma demanda judicial, deferida pelo Tribunal de Justiça do estado do Rio Grande do Sul no sentido de compelir o órgão de saúde estadual a colocar a disposição do impetrante, um menor de 18 anos, cerca de duzentos mil dólares, necessários para a realização de uma cirurgia na NASA, a agencia espacial norte-americana. A cirurgia tinha por objetivo a tentativa de afastar a tetraplegia do Impetrante, decorrente de um disparo acidental de arma de fogo.

Ainda no ano de 1994, identificamos a existência daquele que pode ser o caso mais remoto a tratar de pedido de fornecimento de medicamento pelo Estado no âmbito do STF. Refere-se a pedido de Suspensão de Segurança $n^{\circ} 720 / R^{69}$ contra liminar concedida pelo Tribunal de Justiça do Estado do Rio de Janeiro em face daquele mesmo Estado para que se fornecesse determinada quantidade de medicamento a paciente, durante o período de seis meses, ou a quantia correspondente ao respectivo preço, em dólares, para aquisição no exterior.

O pedido, no entanto, foi indeferido, após sopesados, conforme a decisão, "os riscos opostos, da lesão à economia pública de um lado, e do perigo de vida, a que, de outro, está sujeito o impetrante, para pronunciar-se pela predominância desse último valor". A decisão demonstrou o posicionamento do tribunal que viria a prevalecer até os dias atuais, reconhecendo a obrigatoriedade do Estado em prestar medicamentos levando-se em conta tão-somente uma ponderação de valores ou princípios: de um lado o direito à vida do postulante e, de outro, questões econômico-financeiras.

\footnotetext{
${ }^{68}$ STF. Suspensão de Segurança no 659/RS, relator: Min. Carlos Velloso, julgamento em 22 de julho de 1994, DJ 03/08/1994.

${ }^{69}$ STF. Suspensão de Segurança ${ }^{\circ}$ 720/RJ, relator: Min. Octavio Gallotti, decisão da Presidência, julgamento em 06/12/1994, DJ 13/12/1994.
} 
Posteriormente, em 1998, em decisão monocrática proferida pelo Ministro Marco Aurélio, foi negado o pedido feito no Agravo de Instrumento $\mathrm{n}^{\mathrm{o}} 232.469 / \mathrm{RS}^{70}$ interposto pelo município de Porto Alegre contra acórdão proferido pelo Tribunal de Justiça do Estado do Rio Grande do Sul que determinou aquele município a entrega de medicamentos para tratamento de pessoa portadora do vírus HIV a qual não possuía recursos financeiros para adquiri-los. Neste caso, apesar de tratarse do proferimento de uma decisão monocrática, o reconhecimento do conteúdo da norma disposta no artigo 196 da Constituição Federal como norma de eficácia imediata e aplicabilidade direta, e não como norma meramente programática, bem como, o reconheci-mento do direito a medicamentos ligado ao direito à vida como um direito subjetivo em face do Estado, serão, posteriormente, os principais argumentos utilizados pelos ministros na fundamentação de suas decisões para se obrigar o Estado a fornecer medicamentos de alto custo pleiteados individualmente.

Tal argumentação é reforçada no julgamento do paradigmático Recurso Extraordinário no 271.286/RS em decisão monocrática proferida pelo Ministro Celso de Mello em 02/08/2000 ${ }^{71}$ e no acórdão de agravo no mesmo recurso, julgado em 12/09/2000 72 pela segunda turma do STF, o qual foi negado provimento.

O tema das políticas públicas de saúde, em sua matriz "coletiva", foi tratado no julgamento da $\mathrm{ADPF} \mathrm{n}^{\mathrm{o}} 45$ (não como questão principal), na qual se discutiu sobre a legitimidade constitucional do controle e intervenção do Poder Judiciário em temas relacionados à implementação de políticas públicas, especialmente aquelas relacionadas às ações e serviços de saúde, onde se sustentou a tese do "mínimo existencial" em detrimento da "reserva do possível" e dos limites financeiros do Estado.

Reconhecendo os problemas gerados pelo crescimento do número de demandas judiciais por medicamentos de alto custo, e buscando controlá-las de forma a diminuir seu impacto negativo no sistema público de saúde, o Supremo Tribunal Federal, em 2009, realizou audiência pública sobre a judicialização da saúde, presidida pelo Ministro Gilmar Mendes, onde participaram

\footnotetext{
${ }^{70}$ STF. Agravo de Instrumento 232469/ RS, Relator: Min. Marco Aurélio, decisão monocrática, julgamento em 12 de dezembro de 1998, DJ 23/02/1999.

${ }^{71}$ STF. Recurso Extraordinário 271286/RS, Relator: Min. Celso de Mello, decisão monocrática, julgamento em 02 de agosto de 2000, DJ 23/08/2000.

${ }^{72}$ STF. Recurso Extraordinário 271286-8/RS, Relator: Min. Celso de Mello, Acórdão proferido pela $2^{\mathrm{a}}$ turma em 12 de setembro de 2000, DJ 24/11/2000.
} 
especialistas da área de saúde e do direito, tendo como casos emblemáticos, naquele momento, as Suspensões de Tutela Antecipada (STA) nº 175 e 178.

O agravo na STA 175/CE foi interposto pela União e julgado em 2010, em detrimento do acórdão proferido pela $1^{\mathrm{a}}$ turma do Tribunal Regional Federal da $5^{\mathrm{a}}$ Região, nos altos da apelação civil 408.729/CE. O referido tribunal havia deferido a antecipação de tutela recursal para determinar à União, ao Estado do Ceará e ao município de fortaleza o fornecimento do medicamento denominado "Zvesca" em favor pessoa portadora da doença Niemann-Pick tipo "C" - doença neurodegenerativa rara que causa distúrbios neuropsiquiátricos. O tratamento foi orçado em R \$ 52.000,00 por mês, um valor impossível de ser custeado pela paciente e sua família. Tal medicamento, na época do julgamento, não constava nos Protocolos Clínicos de Diretrizes Terapêuticas do SUS, sendo considerado medicamento de alto custo não contemplado na política farmacêutica da rede pública.

$\mathrm{O}$ alto custo do medicamento, segundo alegou a agravante (União), poderia implicar o deslocamento de esforços e recursos estatais e a descontinuidade da prestação dos serviços de saúde ao restante da população. Rebatendo este argumento, o Ministro Gilmar Mendes em seu voto, que foi acompanhado pelos demais Ministros, afirmou que o alto custo do medicamento não é, por si só, motivo para o seu não fornecimento, visto que a Política de Dispensação de Medicamentos excepcionais visa a contemplar justamente o acesso da população acometida por enfermidades raras aos tratamentos disponíveis.

Por fim, o Recurso Extraordinário no $566.471 / \mathrm{RN}$ foi o último paradigma jurisprudencial da Suprema Corte ao tratar do tema ${ }^{73}$, haja vista que, teve repercussão geral reconhecida em 03 de dezembro de 2007 e se encontra, ainda, em julgamento. No dia 28 de setembro de 2016, votaram três Ministros - Marco Aurélio, Luís Roberto Barroso e Edson Fachin - e, recentemente, no dia 14 de junho de 2019 foi incluído no calendário do STF, para ser julgado no dia 23 de outubro de 2019.

O caso envolveu a recusa por parte do Estado do Rio Grande do Norte em fornecer o medicamento SINDENAFIL, classificado como de alto custo e não previsto no programa de

\footnotetext{
$73 \mathrm{O}$ RE 566.471/RN trata, especificamente, do fornecimento de medicamentos de alto custo. Outros temas relacionados já foram decididos recentemente, como é o caso do fornecimento de medicamentos experimentais ou sem registro na ANVISA, os quais, segundo decidiu o plenário do STF, no dia 22 de Maio de 2019, o Estado não poderá ser obrigado a fornecer, salvo em casos excepcionais, quando houver mora irrazoável da ANVISA em apreciar o pedido de registro. Outro tema correlato foi decidido no julgamento dos embargos de declaração no Recurso Extraordinário $\mathrm{n}^{\circ} 855.178$, em 23/05/2019, sobre a responsabilidade solidária dos entes federados pelo dever de prestar assistência à saúde. STF. RE 855.178. Relator: Min. Luiz Fux. Disponível em: http://portal.stf.jus.br/processos/detalhe.asp?incidente=4678356. Acesso em 24 Mai. 2019.
} 
dispensação de medicamentos, a uma senhora idosa, de baixa renda, portadora de miocardiopatia isquêmica e hipertensão arterial pulmonar. A sentença do juízo de primeiro grau determinou a obrigação de seu fornecimento, sendo confirmada, posteriormente, pelo Tribunal de Justiça daquele Estado.

Os votos proferidos pelos três ministros estabeleceram critérios e parâmetros objetivos, os quais podem ter marcado uma nova fase de discussão sobre o tema. A conclusão que se chega, até o momento, é de que o Estado pode ser obrigado a custear o medicamento de alto custo demandado judicialmente, que não esteja incluído na política nacional de medicamentos ou programa de dispensação de medicamentos, desde que (I) seja demonstrado sua impossibilidade de substituição por outro já incorporado pelo SUS e (II) seja comprovada a incapacidade financeira do enfermo em custeá-lo.

Junto a estes dois critérios (comuns), outros critérios foram apresentados, especificamente, por cada ministro. Para o Min. Marco Aurélio é necessária a demonstração da imprescindibilidade do medicamento. Para o Min. Luís Roberto Barroso é indispensável (I) a demonstração de que a sua não incorporação, não resultou de decisão dos órgãos competentes; (II) a comprovação da sua eficácia à luz da medicina baseada em evidências; (III) a propositura da demanda em face da União; e (IV) a realização de um diálogo institucional entre os Poderes. Já para o Min. Edson Fachin é obrigatório (I) o prévio requerimento administrativo; (II) a prescrição realizada por médico da rede pública; (III) a indicação por meio de DCB ou DCI; e (IV) o laudo ou formulário que indique a necessidade do tratamento, seus efeitos, evidências e vantagens para o paciente.

\section{CONSIDERAÇÕES FINAIS}

Considerando o estado da arte das demandas por medicamentos de alto custo no Supremo Tribunal Federal, verifica-se que, este tem se posicionado a favor do direito a assistência farmacêutica em detrimento do interesse econômico-financeiro do Estado, adotando, portanto, uma perspectiva substancialista do direito. Suas decisões, geralmente, sustentam que as questões de ordem orçamentária não podem obstaculizar a implementação de ações e serviços necessários à efetivação do direito à saúde em sua matriz individual de atendimento. 
A lógica argumentativa do Tribunal admite a existência de limites recursais estatais de ordem financeiro-orçamentária ao considerar a cláusula da reserva do possível como um limite material às prestações estatais positivas. Contudo, não abre mão da garantia de um mínimo existencial que, na prática, se traduz na confirmação da ordem ao Poder Público de entrega do medicamento ao seu postulante, individualmente.

Esta atitude proativa do Tribunal, em relação às políticas públicas de dispensação de medicamentos desenvolvidas pelos demais órgãos da Administração Pública, demonstra que as questões relacionadas ao custo dos direitos são relegadas a um segundo plano, como se qualquer tecnologia existente no mercado mundial de medicamentos fosse passível de ser custada pelo Estado brasileiro. Não obstante a discussão sobre os parâmetros e critérios a serem observados pelos magistrados em tais demandas, verifica-se que não há aprofundamento nas discussões sobre questões envolvendo o valor a ser dispendido pelo Estado e suas consequências para o orçamento público.

A perspectiva pragmática de Sunstein e Holmes sobre os direitos fundamentais, ao trazer luz sobre o problema dos custos a eles inerente, contribui para uma melhor compreensão da problemática envolvendo a efetivação do direito à saúde, pois não é a exaustão da capacidade orçamentária que, necessariamente, frustrará a efetivação dos direitos fundamentais, mas sim a escolha política em se proteger mais (ou parte de) determinado direito em detrimento de outro, haja vista que, todos os direitos têm custos.

\section{REFERÊNCIAIS}

ABRAMOVICH, Víctor; COURTIS, Christian. Los derechos sociales como derechos exigibles. $2^{\mathrm{a}}$ ed. Madrid: Trotta, 2004.

AMARAL, Gustavo. Direito, Escassez e escolha. Em busca de critérios jurídicos para lidar com a escassez de recursos e as decisões trágicas. Rio de Janeiro, São Paulo: Renovar, 2001.

BARCELlOS, Ana Paula. O Direito a Prestações da Saúde: Complexidades, Mínimo Existencial e Valor nas Abordagens Coletiva e Abstrata. In NETO, Claudio Pereira de Souza; SARMENTO, Daniel. Direitos Sociais Fundamentais, Judicilização e Direitos Sociais em Espécie. Rio de Janeiro: Ed. Lumen Juris, 2010.

CASTRO, Paulo Rabello de. O mito do governo grátis: o mal das políticas econômicas ilusórias e as lições de 13 países para o Brasil mudar. Rio de Janeiro: Edições Janeiro, 2014. 
CLÈVE, Emerson Merlin. "O problema da Legitimação do Poder Judiciário e das Decisões Judiciais do Estado Democrático de Direito", Debates, $\mathrm{n}^{\circ}$ 20: A Constituição Democrática Brasileira e o Poder Judiciário. São Paulo: Fundação Konrad Adenauer, 1999. pp. 214-215.

FERRAZ, Octávio Luiz M.; WANG, Daniel Wei L. As duas portas do SUS. Folha de São Paulo, publicado em 19/06/2014. Disponível em: http://www1.folha.uol.com.br/fsp/opiniao/171851-asduas-portas-do-sus.shtml Acesso em: 19/11/2018.

FIGUEIREDO, Mariana Filchtiner. Direito Fundamental à saúde. Parâmetros para sua eficácia e efetividade. Livraria do Advogado: Porto Alegre, 2007.

GALDINO, Flávio. O custo dos direitos. In: TORRES, Ricardo Lobo. A legitimação dos Direitos Humanos. Rio de Janeiro: Renovar, 2002.

GAIER, Reinhard. Prestações positivas contra o Estado e a cláusula da reserva do possível. In: II SEMINÁRIO INTERNACIONAL BRASIL-ALEMANHA, 2011, Florianópolis. Disponível em: http://bit.ly/2uIDaoB . Acesso em: 18 jul. 2017. Organizado pelo Centro de Estudos Judiciários (CEJ) do Conselho da Justiça Federal (CJF). Versão impressa: II Seminário Internacional BrasilAlemanha: Thompson Flores (português-alemão): 16 e 17 de junho de 2011, Florianópolis, Brasil/Conselho da Justiça Federal, Centro de Estudos Judiciários; coordenação científica Márcio Flávio Mafra Leal - Brasília: CJF, 2011. - (Série Cadernos CEJ: 27).

HIRSCHL, Ran. The new constitutionalism and the judicialization of pure politics worldwide. Fordham Law Review, v. 75, n. 2, 2006. Disponível em: https://papers.ssrn.com/sol3/papers.cfm?abstract_id=951610\#\#. Acesso em: 21/02/2019.

PERLINGEIRO, Ricardo. É a reserva do possível um limite à intervenção jurisdicional nas políticas públicas sociais? Revista de Direito Administrativo Contemporâneo, ano 1, v. 2, set./out. 2013.

SARLET, Ingo Wolfgang. Algumas considerações em torno do conteúdo, eficácia e efetividade do direito à saúde na Constituição de 1988. Revista Interesse Público, Belo Horizonte: Editora Fórum, ano 3, n. 12, out. 2001.

SCAFF, Fernando Facury. Você não sabe, mas vive entre a reserva do possível e as escolhas trágicas. Publicado no site Consultor Jurídico em 23/01/2018. Disponível em https://www.conjur.com.br/2018-jan-23/contas-vista-vivemos-entre-reserva-possivel-escolhastragicas. Acesso em: 07/08/2018.

SCHULZE, Clenio. A Judicialização da Saúde no Século XXI. Porto Alegre: Verbo Jurídico, 2018.

SILVA, Virgílio Afonso da. O Judiciário e as políticas públicas: entre transformação social e obstáculo à realização dos direitos sociais. In: NETO, C.; SARMENTO, D. Direitos sociais: fundamentação, judicialização e direitos sociais em espécies. Rio de Janeiro: Lúmen Júris, 2008. 
SUNSTEIN, Cass R.; HOLMES, Stephen. The Cost of Rights: Why Liberty Depends on Taxes. W. W. Norton \& Company: Nova Iorque, 1999.

SUNSTEIN, Cass R. Beyond the Republican Revival. Yale Law Journal 97: 1539-1590 (1988). Disponível https://chicagounbound.uchicago.edu/cgi/viewcontent.cgi?article=12192\&context=journal_articl es. Acessado em: 04/10/2018.

TORRES, Ricardo Lobo. Tratado de Direito Constitucional Financeiro e Tributário. Vol. I Constituição Financeira, Sistema Tributário e Estado Fiscal. Rio de Janeiro: Renovar, 2009.

TRAVASSOS, Cláudia et al . Desigualdades geográficas e sociais na utilização de serviços de saúde no Brasil. Revista Ciência \& saúde coletiva, Rio de Janeiro, v. 5, n. 1, p. 133-149, 2000. Disponível em: http://www.scielo.br/scielo.php?script=sci_arttext\&pid=S141381232000000100012\&lng=en\&nrm=iso. Acesso em: 24 Abr. 2018.

VALLE, Vanice Regina Lírio de. Políticas públicas, direitos fundamentais e controle judicial. Belo Horizonte: Ed. Fórum, 2016.

VILLEY, Michel. Filosofia do direito: definição e fins do direito: os meios do direito. 2.ed. São Paulo: Martins Fontes, 2008.

\title{
JUDICIALIZATION OF HIGH COST MEDICINAL PRODUCTS IN BRAZIL AND THEORY OF COST OF RIGHTS
}

\begin{abstract}
This paper aims to analyze the decisions of the Brazilian Supreme Court in the demands for high cost medicines investigating how the problem of the costs of rights has been treated, ie, the importance (value) given by the Court to the financial-budgetary issues in question. face of ethical-legal arguments such as the existential minimum and the dignity of the human person. Given the growing phenomenon of judicialization of health, the main objective is to analyze the theoretical and practical effects of the discussion about the positive dimension of fundamental rights, from a pragmatic perspective, for the realization of the social right to health, especially pharmaceutical care. Notwithstanding the acknowledgment of the positive dimension present in all rights, when descriptively analyzed, as Cass Sunstein and Stephen Holmes demonstrate, it is verified that Brazilian jurisprudence has maintained that no financial-budgetary argument can limit the right to receive medicines. high cost. Such a position, however, finds it difficult to adapt to the ideals of universality and equality, as well as to distributive justice, as it serves only a portion of the population to the detriment of an even larger one.
\end{abstract}


Keywords: Right to health. High cost medicines. Cost of rights. 